\title{
3
}

\section{Fair Use and Traditional Cultural Expressions}

\author{
Natalie P Stoianoff and Evana Wright ${ }^{1}$
}

\section{Introduction}

Yolngu art is part of the Yolngu system of knowledge both in itself and as a system of encoding meaning. The form of paintings is part of the ancestral knowledge that is transmitted from generation to generation, yet in addition, paintings encode meanings about the ancestral past and are one of the main ways in which people gain access to knowledge of the events of the ancestral past. More than that, paintings ... are involved in the process of creating new meanings and understandings about the world, and in communicating these understandings to others. ${ }^{2}$

Indigenous knowledge may be broadly described as the system of knowledge developed and maintained by Indigenous and local communities and transmitted from generation to generation and includes:

\footnotetext{
1 Copyright (C) 2018 Natalie P Stoianoff and Evana Wright. Professor Natalie Stoianoff is the Director of the Intellectual Property Program at the Faculty of Law, University of Technology Sydney. She is the Chair of the Indigenous Knowledge Forum Committee and Lead Chief Investigator on the ARC Linkage Project Garuwanga: Forming a Competent Authority to Protect Indigenous Knowledge. Dr Evana Wright is a Lecturer in the Faculty of Law, University of Technology Sydney. 2 Howard Morphy Ancestral Connections: Art and an Aboriginal System of Knowledge (University of Chicago Press, 1991) at 75.
} 
[L]iterary, artistic or scientific works; performances; inventions; scientific discoveries; designs; marks; names and symbols; undisclosed information; and all other tradition-based innovations and creations resulting from intellectual activity in the industrial, scientific, literary or artistic fields. ${ }^{3}$

Indigenous knowledge, including traditional cultural expressions, has been subject to misappropriation and exploitation by third-party interests resulting in spiritual, cultural and economic loss for Indigenous and local communities. $^{4}$

To be clear, 'traditional' in the Indigenous knowledge context does not equate to old. Rather than denoting age, the term 'traditional' refers to the process by which the knowledge has been transmitted from generation to generation. The knowledge can be built upon, evolve and develop. Thus, new 'works' (in the copyright sense) can be created that constitute traditional cultural expressions.

The existing copyright system, however, does not provide adequate protection for Indigenous knowledge and cultural expressions that are collectively generated and held by an Indigenous or local community. ${ }^{5}$ Even where protection does extend to traditional cultural expressions as a copyright work, the existing exceptions and limitations established under the copyright system do not take into account the special relationship between Indigenous communities and their cultural production. ${ }^{6}$ Any exception or limitation to copyright must take into account this special relationship, as any use of traditional cultural expressions by a third party may be considered an affront to that community's culture and law.

3 World Intellectual Property Organization (WIPO) 'Intellectual Property Needs and Expectations of Traditional Knowledge Holders: WIPO Report on Fact-Finding Missions on Intellectual Property and Traditional Knowledge 1998-1999' (April 2001) at 25 [WIPO 'Intellectual Property Needs and Expectations of Traditional Knowledge Holders'].

4 Natalie P Stoianoff and others, 'Recognising and Protecting Aboriginal Knowledge Associated with Natural Resource Management - White Paper for the Office of Environment and Heritage' (UTS - Indigenous Knowledge Forum \& North West Local Land Services, NSW, 2014) indigenousknowledgeforum.org at 1-3.

5 Natalie P Stoianoff and Alpana Roy 'Indigenous Knowledge and Culture in Australia - The Case for Sui Generis Legislation’ (2015) 41(3) Mon LR 746.

6 WIPO Intergovernmental Committee on Intellectual Property and Genetic Resources (IGC) Traditional Knowledge and Folklore, The Protection Of Traditional Cultural Expressions: Draft Gap Analysis WIPO/GRTKF/IC/13/5(b) Rev, XIII (2008) at 13-17. 


\section{Traditional Cultural Expressions}

In recent years, the western understanding of Indigenous knowledge has been divided into two categories: traditional knowledge and traditional cultural expressions. ${ }^{7}$ Traditional knowledge involves knowledge, skills, know-how and innovations of Indigenous or local communities, ${ }^{8}$ and this category of knowledge typically aligns with western patent law systems. By contrast, traditional cultural expressions include Indigenous or traditional artworks, music and songs, stories and performances that are typically generated collectively and cumulatively and passed on from generation to generation. ${ }^{9}$ The works that fall within the category of traditional cultural expressions align with the works that may be protected under western copyright law, design law and even trade marks law.

As discussed further below, Indigenous communities do not view their knowledge in the categorical manner used in western intellectual property law. Reflecting a holistic worldview, ${ }^{10}$ traditional cultural expressions are intimately connected to the spiritual, the land or Country and, often, express or communicate knowledge such as traditional medicinal knowledge or information of specific genetic resources. ${ }^{11}$

7 See, for example, efforts by WIPO to develop separate Draft Articles for the protection of the following categories of knowledge: traditional knowledge; traditional cultural expressions; and intellectual property and genetic resources. For the latest draft agreements see WIPO The Protection of Traditional Knowledge: Draft Articles (15 March 2017) www.wipo.int/meetings/en/doc_details. jsp?doc_id=368218; WIPO The Protection of Traditional Cultural Expressions: Draft Articles (16 June 2017) www.wipo.int/meetings/en/doc_details.jsp?doc_id=375036; WIPO Consolidated Document Relating to Intellectual Property and Genetic Resources (15 March 2017) www.wipo.int/ meetings/en/doc_details.jsp?doc_id=368344.

8 WIPO 'Traditional Knowledge’ www.wipo.int.

9 WIPO 'Traditional Cultural Expressions' www.wipo.int.

10 On 'holism' in the international discourse, see Michael Blakeney 'The Negotiations in WIPO for International Conventions on Traditional Knowledge and Traditional Cultural Expressions' in Jessica C Lai and Antoinette Maget Dominicé (eds) Intellectual Property and Access to Im/material Goods (Edward Elgar, Cheltenham, UK, 2016) 227 at 247-254.

11 See, for example, the artwork on the cover page of the report 'Our Culture, Our Future' by Terri Janke and the description of the knowledge depicted in the artwork on the inner cover page. Terri Janke Our Culture, Our Future: A Report on Australian Indigenous Cultural and Intellectual Property Rights (Michael Frankel and Company, 1999) at Cover and Inner Cover. 
Traditional knowledge and cultural expressions have been subject to a variety of forms of norm-setting including through several international instruments, ${ }^{12}$ regional agreements ${ }^{13}$ and national legal and policy instruments. One must remember that these western forms of regulation are additional to pre-existing customary legal systems of the holders/ creators of the traditional knowledge and cultural expressions.

The protection of Indigenous knowledge from misappropriation and exploitation has been the subject of continued debate in the past three decades, with a number of attempts to develop legal frameworks at an international and regional level. The most relevant existing international instruments for the purpose of this paper are the Convention on Biological Diversity (CBD) ${ }^{14}$ and Nagoya Protocol on Access to Genetic Resources and the Fair and Equitable Sharing of Benefits Arising from their Utilisation to the Convention on Biological Diversity (Nagoya Protocol $)^{15}$ as well as the United Nations Declaration on the Rights of Indigenous Peoples (UNDRIP). ${ }^{16}$

The CBD and Nagoya Protocol are focused on the protection of traditional knowledge associated with biological diversity and genetic resources. The CBD requires member countries to 'respect, preserve and maintain knowledge, innovations and practices of indigenous and local communities embodying traditional lifestyles relevant for the conservation and sustainable use of biological diversity' and to ensure that use of traditional knowledge is subject to the prior informed consent or approval and involvement of the relevant Indigenous or local community, and encourage equitable benefit sharing. ${ }^{17}$ The Nagoya Protocol operationalises the access and benefit sharing provisions of the CBD and requires that member countries establish measures to ensure that

12 For example, Rio Convention on Biological Diversity, 1760 UNTS 79; 31 ILM 818 (opened for signature 5 June 1992, entered into force 29 December 1993) [CBD]; Nagoya Protocol on Access to Genetic Resources and the Fair and Equitable Sharing of Benefits Arising from their Utilization to the Convention on Biological Diversity UN Doc. UNEP/CBD/COP/DEC/X/1 (adopted 29 October 2010, entered into force 12 October 2014) [Nagoya Protocol]; and United Nations Declaration on the Rights of Indigenous Peoples, GA Res 61/295 LXI A/RES/61/295 (13 September 2007) [UNDRIP].

13 For example, Secretariat of the Pacific Community Pacific Regional Framework for the Protection of Traditional Knowledge and Expressions of Culture (2002).

14 CBD, above n 12.

15 Nagoya Protocol, above n 12.

16 UNDRIP, above n 12.

17 CBD, above n 12 , art $8(\mathrm{j})$. 
use of traditional knowledge associated with genetic resources is subject to prior informed consent or approval and involvement of the relevant Indigenous or local communities and upon mutually agreed terms. ${ }^{18}$

By contrast, UNDRIP is concerned with the protection of Indigenous knowledge more broadly and recognises the right of Indigenous peoples to: ${ }^{19}$

[M]aintain, control, protect and develop their cultural heritage, traditional knowledge and traditional cultural expressions, as well as the manifestations of their sciences, technologies and cultures, including human and genetic resources, seeds, medicines, knowledge of the properties of fauna and flora, oral traditions, literatures, designs, sports and traditional games and visual and performing arts. They also have the right to maintain, control, protect and develop their intellectual property over such cultural heritage, traditional knowledge, and traditional cultural expressions.

While the terms of UNDRIP are non-binding, the provisions reflect the increasing recognition of the importance of Indigenous rights and the protection of Indigenous knowledge including traditional cultural expressions. This increasing recognition can also be seen in regional agreements for the protection of Indigenous knowledge, including the Pacific Regional Framework for the Protection of Traditional Knowledge and Expressions of Culture, along with national legal and policy instruments. The legal frameworks described above were developed under the western legal system and are in addition to the pre-existing customary legal systems of the holders or creators of the traditional knowledge and cultural expressions which regulate the use of Indigenous knowledge.

The World Intellectual Property Organization (WIPO) is also working to develop international instruments for the protection of Indigenous knowledge from an intellectual property perspective. As a result of collaboration between WIPO and the United Nations Environment Programme (UNEP), responsible for the introduction of the CBD, in 2000 the WIPO General Assembly established the Intergovernmental Committee on Intellectual Property and Genetic Resources, Traditional

18 Nagoya Protocol, above n 12, arts 7, 16. For a discussion on CBD art 8(j) and the Nagoya Protocol, see Jessica C Lai Indigenous Cultural Heritage and Intellectual Property Rights (Springer, Heidelberg, 2014) at 146-152.

19 UNDRIP, above n 12, art 31(1). 
Knowledge and Folklore (IGC). ${ }^{20}$ Working through the IGC, WIPO has prepared draft articles for the protection of traditional knowledge and traditional cultural expressions, and is negotiating an instrument on intellectual property rights and genetic resources, bringing together Indigenous knowledge and intellectual property within the framework of an access and benefit sharing regime. ${ }^{21}$ This process has taken over 15 years and progress towards reaching a set of agreed terms continues to be slow. Despite the delays and the contentious areas remaining to be addressed, the WIPO IGC has identified a number of key provisions necessary for protecting traditional knowledge and traditional cultural expressions, including the scope and beneficiaries of protection, the governance framework for administering rights, and exceptions and limitations. According to the IGC Mandate for 2018/2019, the IGC will: ${ }^{22}$

continue to expedite its work, with the objective of reaching an agreement on an international legal instrument(s) ... relating to intellectual property which will ensure the balanced and effective protection of genetic resources (GRs), traditional knowledge (TK) and traditional cultural expressions (TCEs).

\section{Traditional Cultural Expressions in Australia}

In the Australian context, the traditional cultural expressions of Aboriginal and Torres Strait Islander peoples may be protected to an extent under the Copyright Act 1968 (Cth) as a literary, dramatic, musical or artistic work, or subject matter other than works, such as sound recordings and films, provided the traditional cultural expression in question meets the requirements set out in the legislation including requirements as to originality. For example, contemporary original artwork depicting culturally significant images may satisfy the criteria for

20 Patricia Adjei and Natalie P Stoianoff 'The World Intellectual Property Organisation (WIPO) and the Intergovernmental Committee: Developments on Traditional Knowledge and Cultural Expressions' (2013) 92 Intellectual Property Forum 37.

21 Natalie Stoianoff 'The Recognition of Traditional Knowledge under Australian Biodiscovery Regimes: Why Bother with Intellectual Property Rights?' in Christoph Antons (ed) Traditional Knowledge, Traditional Cultural Expressions and Intellectual Property Law in the Asia-Pacific Region (Kluwer Law International, 2009) 293 at 294. For the latest draft agreements see above $n 7$.

22 Matters Concerning the Intergovernmental Committee on Intellectual Property and Genetic Resources, Traditional Knowledge and Folklore, Assemblies of Member States of WIPO LV (2-11 October 2017) Agenda Item 18 Decision www.wipo.int. 
copyright protection as seen in the case of Bulun Bulun. ${ }^{23}$ Copyright law vests ownership of a work in the author of that work; however, in the case of traditional cultural expressions, this fails to recognise the rights of the Aboriginal or Torres Strait Islander community to which the author belongs and the obligations that the author owes to their community. Australian courts have recognised the obligations that an author may owe to their community and have sought to characterise this obligation to community as a fiduciary duty: ${ }^{24}$

The relationship between Mr Bulun Bulun as the author and legal title holder of the artistic work and the Ganalbingu people is unique. The 'transaction' between them out of which fiduciary relationship is said to arise is the use with permission by $\mathrm{Mr}$ Bulun Bulun of ritual knowledge of the Ganalbingu people, and the embodiment of that knowledge within the artistic work. That use has been permitted in accordance with the law and customs of the Ganalbingu people ...

This approach is insufficient to fully reflect the rights and responsibilities of a creator or author and their respective Aboriginal or Torres Strait Islander community to traditional cultural expressions. Characterising the relationship as a fiduciary duty does not recognise the rights and obligations that the Aboriginal or Torres Strait Islander community has as the custodian or holder of such traditional cultural expressions: ${ }^{25}$

Whilst the nature of the relationship between Mr Bulun Bulun and the Ganalbingu people is such that Mr Bulun Bulun falls under fiduciary obligations to protect the ritual knowledge which he has been permitted to use, the existence of those obligations does not, without more, vest an equitable interest in the ownership of the copyright in the Ganalbingu people. Their primary right, in the event of a breach of obligation by the fiduciary is a right in personam to bring action against the fiduciary to enforce the obligation.

23 Bulun Bulun v R \& T Textiles Pty Ltd [1998] FCA 1082.

24 Bulun Bulun v R $\varangle$ T Textiles Pty Ltd, above n 23. For analyses of this decision, see Colin Golvan 'The protection of At the Waterhole by John Bulun Bulun: Aboriginal Art and the Recognition of Private and Communal Rights' in Andrew T Kenyon, Megan Richardson, Sam Ricketson (eds) Landmarks in Australian Intellectual Property Law (Cambridge University Press, New York, 2009) 191; and Kathy Bowrey 'The Outer Limits of Copyright Law - Where Law Meets Philosophy and Culture' (2001) 12(1) Law and Critique 75 at 78-84.

25 Bulun Bulun $v$ R $\&$ T Textiles Pty Ltd, above n 23. 
Both the Aboriginal or Torres Strait Islander community and the author or creator hold the responsibility for maintaining and protecting traditional cultural expressions and therefore the community has a particularly important role to play in the context of making decisions as to how traditional cultural expressions may be used and who may provide consent to such use. In his analysis of Yolngu art, Howard Morphy noted: ${ }^{26}$

Yolngu art is part of a system of restricted knowledge in that not all people appear to have equal access to the knowledge contained within it. Secrecy appears to intervene to affect who can learn what.

This aspect of cultural law has implications for the application of fair use provisions under copyright and will be considered below.

Various other elements of copyright protection also fail to adequately protect traditional cultural expressions. For example, the term of copyright protection limits protection to a specific time frame, whereas the obligations and responsibilities that an Aboriginal or Torres Strait Islander community has with regards to the protection of traditional cultural expressions extend in perpetuity. ${ }^{27}$

Copyright must balance the interests or rights of an author or creator with the rights of users to access and use a copyright work. However, in the context of traditional cultural expressions, this issue moves beyond the economic or commercial considerations and requires an understanding of the cultural and spiritual obligations that inform the creation and use of traditional cultural expressions. As observed by the Australian Law Reform Commission (ALRC) in its report on Copyright and the Digital Economy: 'Moral rights and cultural considerations, in particular issues relating to Indigenous culture and cultural practices, need always to be considered, alongside economic rights'. ${ }^{28}$

The potential conflict between the exceptions and limitations established under the copyright system and the rights of Aboriginal and Torres Strait Islander peoples to control the use of copyright material is of concern. This is particularly the case with regards to proposed fair use exceptions to copyright infringement. Fair use provisions are intended to ensure that users have fair access to copyright content while ensuring

26 Morphy, above n 2.

27 See Copyright Act 1968 (Cth), ss 33, 34, 93, 94, 95 and 96, setting out the duration of copyright. For further discussion, see Lai, above n 18, at 78-85.

28 Australian Law Reform Commission (ALRC) Copyright and the Digital Economy (ALRC Report 122, November 2013) at 42 [2.7]. 
that copyright still provides sufficient protection and incentives for the creators of copyright works. In 2013, the ALRC recommended the introduction of a fair use exception into copyright law that would operate with reference to certain fairness factors. The introduction of a fair use exception has more recently been endorsed by the Productivity Commission in their report into Intellectual Property Arrangements. ${ }^{29}$ The Australian Government response to the report on this issue was to acknowledge the need for further consultation while confirming the aim 'to create a modernised copyright exceptions framework that keeps pace with technological advances and is flexible to adapt to future changes'. ${ }^{30}$ This paper will now consider the proposed fair use exception and the impact of such a provision on the creation and use of traditional cultural expressions in Australia.

\section{Fair Use and Traditional Cultural Expressions in Australia}

Copyright law in Australia currently has limited fair dealing exceptions to infringement and these exceptions do not apply consistently across all forms of copyright material. The ALRC has proposed the introduction of a fair use exception to copyright infringement in their report Copyright and the Digital Economy on the grounds that a broad, flexible exception would encourage innovation and provide a flexible standard that could easily 'adapt to new technologies and new commercial and consumer practices'. ${ }^{31}$ The proposed fair use exception would be subject to consideration of certain fairness factors, and a non-exhaustive list of proposed fairness factors are identified by the ALRC in their report as: ${ }^{32}$

a. the purpose and character of the use;

b. the nature of the copyright material;

c. the amount and substantiality of the part used; and

d. the effect of the use upon the potential market for, or value of, the copyright material.

29 See Productivity Commission Intellectual Property Arrangements (Inquiry Report No. 78, Canberra, 2016) Recommendation 6.1.

30 'Australian Government Response to the Productivity Commission Inquiry into Intellectual Property Arrangements' (August 2017) at 7.

31 ALRC, above $\mathrm{n} 28$, at 95 [4.39].

32 ALRC, above n 28, at 144 [Recommendation 5-2]. 
The ALRC has also provided a non-exhaustive list of examples of fair use including use for the purpose of research or study; education; criticism or review; parody or satire; reporting the news; professional advice; quotation; non-commercial private use; access for people with disability; incidental or technical use; and library or archive use. ${ }^{33}$

The introduction of a fair use exception to replace the existing fair dealing provisions has also received support from the Productivity Commission. In its Inquiry Report on Intellectual Property Arrangements, the Productivity Commission argued that the current fair dealing exceptions are too narrow and prescriptive, do not reflect the way people today consume and use content in the digital world, and do not accommodate new legitimate uses of copyright material'. ${ }^{34}$ Reflecting the arguments previously raised by the ALRC, the Productivity Commission observed that an important and positive feature of fair use is its flexibility when compared to the prescriptive nature of the current fair dealing exceptions. ${ }^{35}$

While the proposed fair use exception is intended to encourage fair use while balancing the rights of creators of copyright material, consideration must be given to whether the application of fair use exceptions to the infringement of copyright material is appropriate in the context of traditional cultural expressions. Any fair use exception needs to take into account the special relationship between Aboriginal and Torres Strait Islander communities and their cultural production, as any use by a third party may be considered an affront to, or inconsistent with, that community's culture and law. Given that the proposed fair use provisions are intended as a flexible defence, the application of fair use provisions to use of traditional cultural expressions should be subject to the rights and interests of the relevant Aboriginal or Torres Strait Islander community.

The second fairness factor proposed by the ALRC provides the opportunity to factor in the nature of the copyright work in determining whether a proposed use is 'fair use' for the purpose of the exception to infringement. This second fairness factor may therefore be utilised to provide guidance on dealing with Aboriginal and Torres Strait Islander cultural production including traditional cultural expressions. The application of fair use exceptions to traditional cultural expressions should be subject to broad

33 ALRC, above n 28, at 150-151 [Recommendation 5-3].

34 Productivity Commission, above n 29, at 165.

35 Productivity Commission, above n 29, at 165. 
consultation with Aboriginal and Torres Strait Islander communities to determine the principles that should inform any determination as to fair use.

In addition, the application of fair use exceptions should not erode the moral rights of the author as established under Part IX of the Copyright Act 1968 (Cth). Moral rights accrue to the author (or performer) of copyright material and provide for the right of attribution of authorship; the right not to have authorship falsely attributed and, most importantly for the purpose of this paper, the right of integrity of authorship. The right of integrity is the 'right not to have the work subjected to derogatory treatment' and this includes any material distortion, mutilation, material alteration or other act that is prejudicial to the author's honour or reputation. ${ }^{36}$ Indeed, it may be argued that respect for Aboriginal and Torres Strait Islander peoples' works is a subset of the broader right of integrity of authorship. Despite this, moral rights do not provide sufficient rights to protect traditional cultural expressions from culturally or spiritually inappropriate use. As noted above, moral rights accrue to the author or performer and the Aboriginal or Torres Strait Islander community does not have any right to assert in the case of inappropriate use of their traditional cultural expressions. Rather, the community must rely on the relevant author or performer to assert the rights in relation to the traditional cultural expression.

There are a number of existing protocols that may provide guidance in determining the principles that would inform the application of fair use exceptions to traditional cultural expressions. These protocols are typically framed in ethical and moral conduct, and apply to using and working with Aboriginal and Torres Strait Islander cultural production, including traditional cultural expressions. For example, these include the Museums Australia protocol titled 'Continuous Cultures, Ongoing Responsibilities: Principles and Guidelines for Australian Museums Working with Aboriginal and Torres Strait Islander Cultural Heritage'; ${ }^{37}$ and the Aboriginal and Torres Strait Islander Library, Information and Resource Network protocols, most recently published in 2010 but originally published in 1995 by the Australian Library and Information

36 Copyright Act 1968 (Cth), ss 195AI, 195AJ, 195 AK and 195 AL.

37 Museums Australia 'Continuous Cultures, Ongoing Responsibilities: Principles and Guidelines for Australian Museums Working with Aboriginal and Torres Strait Islander Cultural Heritage' (February 2005) www.nma.gov.au. 
Association. ${ }^{38}$ The Australia Council has also developed protocols that provide guidance for working with Aboriginal and Torres Strait Islander artists in the production of music, writing, visual arts, media arts and performing arts. ${ }^{39} \mathrm{~A}$ number of common elements inform these existing protocols, including the principles of respect; Aboriginal or Torres Strait Islander control; communication, consultation and consent; interpretation, integrity and authenticity; secrecy and confidentiality; attribution and copyright; proper returns and royalties; continuing cultures; and recognition and protection. ${ }^{40}$

The reviews of the copyright system in Australia described above, as well as the proposed Asian Pacific Copyright Code, ${ }^{41}$ provide an opportunity to address the treatment of traditional cultural expressions within a copyright framework. Any reform to the copyright system would require consideration of special provisions to address issues specific to the protection of traditional cultural expressions, including communal rights to authorship; the duration of rights; and the applicability of originality requirements. However, amendments to the copyright system can only go so far and despite the best intentions may not provide adequate protection for the rights of Aboriginal and Torres Strait Islander peoples. As discussed above, Indigenous knowledge is a holistic concept and covers both traditional knowledge and traditional cultural expressions. ${ }^{42}$ Any attempt to protect traditional cultural expressions as distinct from traditional knowledge fails to recognise the holistic nature of Indigenous knowledge systems where, as observed by Morphy above, traditional knowledge is often expressed in traditional cultural expressions. ${ }^{43}$ This raises the question: how do we separate the expression and the knowledge when Indigenous communities do not? It is surely inadequate to keep layering requirements, guidelines and protocols as a means of providing

38 Aboriginal and Torres Strait Islander Library, Information and Resource Network 'Aboriginal and Torres Strait Islander Protocols for Libraries, Archives and Information Services' (2010) atsilirn. aiatsis.gov.au.

39 Australia Council 'Protocols for Working with Indigenous Artists' (2007) www.australiacouncil. gov.au. Music: 'Protocols for Producing Indigenous Australian Music' (2007); Writing: 'Protocols for Producing Indigenous Australian Writing' (2007); Visual Arts: 'Protocols for producing Indigenous Australian Visual Arts' (2007); Media Arts: 'Protocols for Producing Indigenous Australian Media Arts' (2007); Performing Arts: 'Protocols for Producing Indigenous Australian Performing Arts' (2007).

40 Australia Council for the Arts 'Protocols for Producing Indigenous Australian Visual Arts' (2007).

41 Adrian Sterling 'Asian Pacific Copyright Code' in this volume.

42 WIPO 'Intellectual Property Needs and Expectations of Traditional Knowledge Holders', above n 3,86 .

43 See also WIPO 'Intellectual Property Needs and Expectations of Traditional Knowledge Holders', above n 3 , at 86. 
protection when existing intellectual property regimes fall short. Given this inadequacy on the part of western intellectual property systems, a sui generis approach may prove a better alternative. The following section of this chapter focuses on a particular project, which approached the protection of Indigenous knowledge systems and their cultural expression in a more holistic manner.

\section{A Sui Generis Regime for the Protection of Traditional Cultural Expressions?}

Given the inadequacy of the western intellectual property system to provide protection for Indigenous knowledge systems, there is scope to establish a sui generis framework that may address the issues raised above. ${ }^{44}$ This was the focus of the 2014 White Paper, 'Recognising and Protecting Aboriginal Knowledge associated with Natural Resource Management', prepared for the Office of Environment and Heritage New South Wales (NSW) (the White Paper). ${ }^{45}$ While focused on Aboriginal knowledge systems in relation to the natural environment, the White Paper provides a potential blueprint for protecting cultural knowledge and expressions, together with a governance framework for managing access and benefit sharing arrangements over such knowledge and expressions. Commissioned by the Namoi Catchment Management Authority (now North West Local Land Services), under the NSW Office of Environment and Heritage, the White Paper represents the efforts of an extensive Working Party comprising both Indigenous and non-Indigenous experts, brought together under the umbrella of the University of Technology Sydney (UTS) Indigenous Knowledge Forum to: ${ }^{46}$

1. identify key elements of a regime that would recognise and protect Indigenous knowledge associated with natural resource management;

2. facilitate Aboriginal community engagement in the process of developing a regime;

44 See also Lida Ayoubi, 'Copyright Harmonisation in the Asian Pacific Region: Weaving the Peoples Together?' in this volume.

45 Stoianoff and others, above $\mathrm{n} 4$.

46 Indigenous Knowledge Forum 'Recognising and Protecting Indigenous Knowledge Associated with Natural Resource Management' www.indigenousknowledgeforum.org. 
3. develop a draft regime that not only accorded with the aims and goals of North West NSW Aboriginal communities but would be a model for implementation in other regions in NSW;

4. produce a Discussion Paper through which the draft regime could be distributed for comment; and

5. conduct community consultations to refine the draft regime into a model that may be implemented through NSW legislation by finalising a White Paper to be delivered by the UTS Indigenous Knowledge Forum and North West Local Land Services to the NSW Office of Environment and Heritage.

Terri Janke encapsulates succinctly the reason for embarking upon such a project: ${ }^{47}$

A major concern of Indigenous people is that their cultural knowledge of plants, animals and the environment is being used by scientists, medical researchers, nutritionists and pharmaceutical companies for commercial gain, often without their informed consent and without any benefits flowing back to them.

In order to fill the gap in NSW legislation for the recognition and protection of Aboriginal knowledge, this project was carried out in three stages, utilising the experience of other jurisdictions, Australia's international obligations, and the active participation of Aboriginal communities to develop a model law that addresses the concern identified by Terri Janke.

Stage 1 comprised developing a comparative framework, commencing with collecting and analysing legislative and policy regimes already in existence in other parts of the world. Key criteria in each regime were identified and then compared to international obligations and instruments. ${ }^{48}$ This provided the comparative framework upon which a standard-setting model could be developed to ensure the recognition and protection of Indigenous knowledge as part of a living culture. This comparative study considered the countries of Afghanistan, Angola, Argentina, Brazil, Chile, China, Costa Rica, Ecuador, Ethiopia, Hong Kong, India, Kenya, Malaysia, Peru, Philippines, South Africa and Vanuatu, whose laws relating to traditional knowledge, cultural expressions and genetic resources provided useful examples upon which

47 Terri Janke 'Biodiversity, Patents and Indigenous Peoples' (26 June 2000).

48 Including the CBD, Nagoya Protocol, UNDRIP and the Draft Articles of the Intergovernmental Committee of the WIPO; above $\mathrm{n} 7$ and 12. 
an Australian model could draw. In particular, the laws of Brazil, Costa Rica, Ethiopia, Peru, India, Kenya and South Africa provided relevant alternatives to inform the Working Party in developing the model law.

In Stage 2, the Working Party utilised the comparative study to develop a draft regime that meets the elements of supporting a living Aboriginal culture with improved access to Country through recognition and protection of Indigenous knowledge about Country. The resulting Discussion Paper identified 14 provisions that were necessary for the model law: ${ }^{49}$

1. Subject matter of protection - traditional knowledge, traditional cultural expressions, genetic resources;

2. Definition of terms - key terms used in the draft;

3. Scope - what is covered, respect for traditional ownership, respect for sovereignty over genetic resources, moral rights;

4. Beneficiaries - who should benefit;

5. Access - who speaks for Country, process for granting or refusing access including:

a. Prior informed consent - ensuring traditional owners are aware of their rights and significance of agreements made;

b. Mutually agreed terms - ensuring the bargaining process is fair and equitable;

6. Benefit sharing - how are benefits shared, what types of benefit, dealing with technology transfer, capacity building;

7. Sanctions and remedies - dealing with breaches;

8. Competent authority - establishment of a body to administer the legislation, deal with education, model clauses, codes of conduct, databases;

9. No single owner - addressing situations where traditional knowledge, cultural expressions, genetic resources are common to more than one group;

10. Exceptions - emergencies, traditional use, conservation;

49 Indigenous Knowledge Forum \& North West Local Land Services (formerly Namoi CMA) Recognising and Protecting Aboriginal Knowledge Associated with Natural Resource Management (Discussion Paper 1, 2014) www.indigenousknowledgeforum.org/indigenous-knowledge-naturalresour at $9-10$. 
11. Disclosure - permits, databases, disclosure in intellectual property applications;

12. Interaction with existing laws - avoiding conflict with other laws;

13. Recognition of requirements of other nations - mutual recognition of rights and ensuring compliance;

14. Transitional provisions - existing uses.

Stage 3 involved distributing the Discussion Paper through North West Local Land Services to the Aboriginal communities of the North West NSW region and other interested parties. Then, consultation sessions were organised to meet with Aboriginal communities in key locations in the North West region, including Tamworth, Gunnedah, Walgett and Narrabri, in order to explain the proposed model and enable frank discussion. These focus group sessions enabled the draft regime to be refined into a model that could be implemented through legislation. To this end, a draft White Paper proposing the legislation was prepared and refined with the assistance of the Working Party. At the Second Indigenous Knowledge Forum, held in Sydney on 2 and 3 October 2014, the White Paper was delivered to the chief executive officer of the Office of Environment and Heritage. In a recent communication from the Office of the Minister for Environment, Planning and Heritage, the White Paper has been taken into account in the development of a proposed new system for managing and conserving Aboriginal cultural heritage in NSW.

The model presented in the White Paper provides draft legislation that aims to protect the knowledge held by Aboriginal communities in NSW. The language of the draft legislation avoids reference to 'property rights' in the knowledge and cultural expressions, as communities view their rights as custodial rights. The important aspect of this legislation is the recognition that Aboriginal communities have the right to control the knowledge they hold in accordance with customary law, now more frequently referred to as 'First law' in recognition of the First Nations of Australia. This means that others can only use that knowledge or cultural expression with the prior informed consent of the relevant Aboriginal community. In addition, the draft legislation ensures that where others are given permission to use the knowledge or cultural expression, the relevant Aboriginal communities get benefits for sharing their knowledge and cultural expressions. 
This could be perceived as a counterpoint to the concept of fair use. As discussed above, exercise of a fair use exception would enable any third party to utilise Aboriginal cultural production without obtaining permission from the authors, let alone the relevant community, provided the use is in line with the fairness factors. However, 'fair use' is intended to be a flexible defence, and so a copyright work that is a cultural expression emanating from an Aboriginal community could have the requirement that permission be first sought from the community before the expression can be utilised by a third party.

It should be noted that the model proposed in the White Paper is a principles-based framework designed to address the following questions:

- What is knowledge?

- Who should speak for the knowledge?

- Who should benefit from the knowledge being shared with others?

- Should there be particular types of benefit?

- What should happen if there are disagreements?

- What sort of organisation should look after these matters?

- What sort of databases (if any) are appropriate?

- What should happen if knowledge is owned by more than one community?

It was recognised that there would be gaps in the draft legislation that would require regulations to ensure the proper operation of the legal regime: even so, the White Paper provides a case study to demonstrate how the draft legislation is intended to operate. ${ }^{50}$

An issue of particular concern to the communities consulted in the White Paper process related to the competent authority necessary to manage the access and benefit sharing regime created by the draft legislation. The proposed legislative competent authority would provide the governance framework for administering a legal regime covering the creation, maintenance and protection of Aboriginal community knowledge databases. However, community consultation raised concerns about the form such an authority would take, its independence from government, how it would be funded and wound up, local Aboriginal representation and engagement.

50 Stoianoff and others, above n 4, at 83-91. 
Back in 2009, Terri Janke proposed an independent National Indigenous Cultural Authority as the appropriate form of a competent authority. ${ }^{51}$ This was reinforced in 2013 by the National Congress of Australia's First Peoples espousing such a regime, and identifying various characteristics whereby the Authority should be independent from government, with its own legal status, board of governance, constitution and representing members. ${ }^{52}$ The board would be elected from its grassroots membership base but also allow for the necessary skills based director representation. The Congress recognised a need for further research, funding and support to investigate how to best establish an Authority with these characteristics. This is the focus of the Australian Research Council Linkage Project called 'Garuwanga: Forming a Competent Authority to Protect Indigenous Knowledge', representing the follow-on project from the White Paper.

The community consultations undertaken for the White Paper revealed some important considerations: support for an entity to administer the proposed regime; importance of the independence of such an entity; 'concern regarding the functions of this entity being administered by one or more existing agencies' while acknowledging 'the need for the Competent Authority to include a local or regional community agency to administer the Knowledge Holder registers and provide for Community Knowledge databases'; a 'need for confidential information to be protected'; that an appeal process be established as well as 'a process for ensuring benefits under the control of the Competent Authority are applied and are not lost if the Authority is wound up'. ${ }^{53}$ The consultations revealed community mistrust of government-based organisations, and the failings of past Indigenous bodies to fulfil community expectations. ${ }^{54}$ Accordingly, the Garuwanga project builds on the White Paper, aiming to recommend a legal structure for the competent authority while addressing the issues raised in the community consultations. ${ }^{55}$ It follows a similar methodology to that of the White Paper, adding:

51 Terri Janke Beyond Guarding Ground: A Vision for a National Indigenous Cultural Authority (Terri Janke and Co, Rosebery, NSW, 2009).

52 National Congress of Australia's First Peoples The Call for a National Indigenous Cultural Authority (position paper on National Indigenous Cultural Authority, 2013).

53 Stoianoff and others, above $\mathrm{n} 4$, at 33-52.

54 Ibid.

55 Examples of relevant legal structures include Aboriginal and Torres Strait Islander corporations, and corporations under s 57A of the Corporations Act 2001, including incorporated and unincorporated associations, trust arrangements involving such organisations, statutory bodies and Aboriginal Land Councils. 
- identifying the key features of the variety of legal structures utilised by other nations employing a competent authority governance framework;

- evaluating those legal structures through a research roundtable;

- proposing a workable model; and

- obtaining feedback through community consultation.

\section{The Opportunity of an Asian Pacific Copyright Code}

Adrian Sterling's 2015 proposal for an Asian Pacific Copyright Code brings to light the need to consider the issues and concerns of the nations located within the region. We would go so far as to say that any regional copyright code must heed the cultural expectations of the member states in that region. The Asian Pacific region is replete with rich traditional and/or Indigenous cultures, each with their own customary laws and protocols. These need to be at least acknowledged and in some way incorporated into such a plurilateral instrument, even though that instrument is grounded in western intellectual property law: ${ }^{56}$

Two general aims of the Code principles are firstly, to incorporate the principles recognised in the relevant international copyright and related rights instruments, and secondly, to incorporate on particular points higher standards of protection than in these instruments.

Specifically, Part II Section C Rights provides a perfect opportunity to introduce the rights of traditional or Indigenous communities to their knowledge and cultural expressions. This could be achieved by reference to sui generis legislation that is already in place in the region or by a specific provision. Under Section D Limitations and exceptions, it would be important to note that an exclusion such as fair use should have some form of specific operation when dealing with traditional or Indigenous knowledge and cultural expression. The fairness factors could have a separate category for such cultural production which would enable reference to sui generis legislation or to a particular protocol or set of protocols in order to achieve a result regarding use by third parties. Equally, improving the nature of moral rights could serve to provide another layer

56 Sterling, above n 41 . 
of protection of the Indigenous knowledge and culture. Certainly, the most effective form of protection would be through sui generis legislation where non-compliance could result in sanctions and thereafter the use of protocols, which tend to be non-compulsory unless they are tied to funding schemes.

\section{Conclusion}

This chapter considered the place held by Indigenous cultural production in the sphere of copyright and the benefit of employing sui generis legislation to deal with the nuances of protection and use of that production. A potential blueprint for such a legal regime has been provided by the White Paper and appears to be gaining traction in NSW at present. Specifically, this chapter has addressed the issue of fair use in the context of the recommendations of the ALRC and the Productivity Commission, respectively. This is contrasted with the need for Aboriginal communities to have the right to control the use of that cultural production and to receive a fair level of compensation for such use. The proposed Asian Pacific Copyright Code provides an opportunity to consider how traditional or Indigenous cultural production in the region can be protected and how the specific exception of fair use can be moderated in this context. 
This text is taken from Making Copyright Work for the Asian Pacific: Juxtaposing Harmonisation with Flexibility, edited by Susan Corbett and Jessica C Lai, published 2018 by ANU Press, The Australian National University, Canberra, Australia.

doi.org/10.22459/MCWAP.10.2018.03 